Published in "Ergonomics $52(3)$ : 302-311, March 2009"

which should be cited to refer to this work

\title{
The predictive qualities of operator characteristics for process control performance: The influence of personality and cognitive variables
}

\author{
Dina Burkolter ${ }^{\mathrm{a} *}$, Annette Kluge ${ }^{\mathrm{a}}$, Jürgen Sauer ${ }^{\mathrm{b}}$ and Sandrina Ritzmann ${ }^{\mathrm{a}}$ \\ ${ }^{a}$ Research Institute for Organizational Psychology, University of St. Gallen, Varnbüelstrasse 19, CH-9000 St. Gallen, Switzerland; \\ ${ }^{b}$ Department of Psychology, University of Fribourg, Rue de Faucigny 2, CH-1700 Fribourg, Switzerland
}

\begin{abstract}
This article examines the relationship between operator characteristics and process control performance. Thirty-nine trainee operators participated in a 4-h training session of a simulated process control task and a testing session in which various system faults had to be managed. Cognitive ability, cognitive flexibility, self-efficacy and personality traits were measured as operator characteristics. Cognitive ability related positively to system control performance but not to diagnostic performance. Participants with low cognitive flexibility performed best on system control, whereas participants with high cognitive flexibility performed best on diagnostic performance. A hierarchical regression analysis revealed that cognitive ability, cognitive flexibility and declarative knowledge accounted for about $30 \%$ of the variability of system control. The findings suggest that consideration of cognitive ability and cognitive flexibility be increased in personnel selection for complex work environments.
\end{abstract}

Keywords: process control; individual characteristics; personnel selection; performance

\section{Introduction}

Safety, reliability and productivity have long been key objectives in process control environments such as refineries and nuclear power plants. They remain high priorities for process industries because human errors and their consequences may cause severe damage for nature and human beings (Wickens and Hollands 2000). How can these goals be achieved? There are different ways in which organisations strive for high reliability and safe production. One typical approach in the field of ergonomics is to increase the emphasis on system or task design, that is, to improve systems or interfaces in order to enhance operators' performance. The focus is thus on improving the machine side of the human-machine system. However, highly reliable and safe production cannot be achieved by tending only to the complex system and its components; it depends on qualified and competent personnel as well (International Atomic Energy Agency 1996). Enhancing the qualification of personnel through regular training is therefore an additional approach taken by organisations. A third way to contribute to safety, reliability and productivity in process control industries is to select personnel, such as process control operators, who are most likely to succeed at their jobs. This raises the question of which operator characteristics can best predict process control performance.
There is a small branch of ergonomic research that addresses issues of individual characteristics, performance and personnel selection. Hollnagel (1998), for instance, differentiates between temporary personrelated variables (e.g. inattention and fatigue) and permanent person-related variables (e.g. variables relating to cognition), both of which are linked to human errors. Wickens et al. (1998) address the matter of selection in human factors engineering, drawing on many empirical findings from aviation research, a field in which this subject has long figured prominently (Hunter and Burke 1994). Coverage of empirical findings on selection in process control environments is harder to come by.

Three reasons are advanced to explain the lack of research on the selection of process control operators (Williams and Taylor 1993, Stanton and Ashleigh 1996). First, research on operator selection is considered complex because of the methodological problems entailed by this type of study. For instance, the infrequency and irregularity of events in process control make it difficult to measure actual job performance. Second, human factors researchers might feel that selection has little effect on work performance in comparison to aspects such as system design and operator training. Third, research has shown that predictive power is quite poor (Stanton and Ashleigh 1996). However, Stanton and Ashleigh (1996) argue 
that this assessment becomes a "circular argument: because it is a difficult area to study and people perceive that it is less important than other areas, little research is done, so the predictive power of the methods is not optimised' (p. 181). The aim of this article is to improve understanding of how operator characteristics such as cognitive ability and style, selfefficacy and personality relate to process control performance.

\subsection{Selection of process control operators}

Within the process control industries, the nuclear industry appears to have the most standardised procedures for personnel selection. Stating that the selection of suitably qualified personnel is essential for the safe and reliable operation of a nuclear power plant, the International Atomic Energy Agency (IAEA) provides recommendations and guidelines for the recruitment of plant personnel (e.g. International Atomic Energy Agency 2002, 2006). Recruitment of personnel is expected to follow approved procedures that include both the specification of selection criteria and objective testing to assess applicants' aptitudes for the job (International Atomic Energy Agency 2002). Aside from education, IAEA-recommended selection criteria are work background and experience, problemsolving ability, emotional stability, motivation, initiative, communication skills and attitudes towards safety. Attributes related to safety culture include 'a questioning attitude, a rigorous and prudent approach and communication and learning abilities' (International Atomic Energy Agency 2002, p. 5).

In a survey of selection methods that was carried out in 34 organisations in 13 countries of the nuclear industry, Stanton and Ashleigh (1996) showed that interviews and references were the most frequently employed methods, followed by personality and cognitive tests that were applied by more than $60 \%$ of the organisations. Tests are employed to predict performance and to ensure that applicants are sufficiently qualified. It is thereby assured that 'training resources are not wasted on candidates who are unfit for the job' (International Atomic Energy Agency 2006, p. 3). Personality characteristics such as honesty, integrity and attitudes are assessed as well and interest inventories are used. Different methods are chosen depending on which attributes are of primary interest. Written tests are administered to assess knowledge; oral tests, to assess knowledge and attitudes; and performance examinations, to assess skills and attitudes (International Atomic Energy Agency 2006). However, it remains unclear just how abilities, personality or other individual characteristics affect performance, whether all characteristics are equally important for predicting job success, which of them are essential and which are simply 'nice to have'.

\subsection{Operator characteristics and their effect on performance}

Individual characteristics that affect work performance in general include cognitive abilities and style, selfefficacy and personality traits (e.g. Morris and Rouse 1985, Colquitt et al. 2000). Each of these characteristics exhibited by the applicant or expected to be critical particularly for process control performance are addressed below. This review of individual characteristics thus rests on empirical research on complex systems and process control, but it is also complemented by research in related fields (e.g. aviation) because empirical research on this topic in the field of process control is rather scarce.

\subsubsection{Cognitive ability}

Across many work environments a strong relationship between cognitive ability and performance has been shown to exist indirectly through job knowledge (Schmidt and Hunter 1998). Regarding process control and related tasks, Morris and Rouse (1985) found in their review that cognitive ability was related to troubleshooting performance and that measures of job-related knowledge and skills had the highest relationships to performance.

A large number of interrelated variables account for a high level of complexity in process control (Wickens and Hollands 2000). Controlling complex systems therefore requires different aspects of cognitive ability. First, an operator needs reasoning ability in order to develop hypotheses about the causal structure of the system. Second, reasoning with numbers has proven to be a predictor of performance in dealing with simulated complex systems (Wittmann and Hattrup 2004, Kluge 2008). Third, an operator requires verbal and figural abilities in order to understand instructions, information and graphs given by the system (Wittmann and Hattrup 2004, Kluge 2008). Drawing on the empirical results presented in the literature, it is hypothesised that cognitive ability is positively related to process control performance.

\subsubsection{Cognitive flexibility}

Several measures of cognitive style such as field independence-dependence and reflectivity-impulsivity have been shown to be related to troubleshooting performance (Morris and Rouse 1985). Cognitive flexibility as a cognitive style is described by Spiro et al. 
(1996) as a reductive and an expansive style of thinking. Individuals with a reductive cognitive style (i.e. low cognitive flexibility) have a preference for simplicity and rigid prescriptions from memory and an intolerance of ambiguity. Individuals with an expansive and flexible cognitive style (i.e. high cognitive flexibility) assume the world to be heterogeneous and have a flexible and situation-adaptive assembly of knowledge. Supported by empirical findings, Spiro et al. (1996) argue that individuals with high cognitive flexibility are more likely to perform required cognitive operations for knowledge acquisition in complex and ill-structured domains. Also, individuals with high cognitive flexibility are more qualified to learn in novel, complex situations. Following Spiro et al. (1996), it was expected that cognitive flexibility would be positively associated with the handling of complex systems.

\subsubsection{Self-efficacy}

A meta-analysis by Stajkovic and Luthans (1998) has shown self-efficacy to be correlated to work-related performance. As for complex problem solving, Debowski et al. (2001) found a positive relationship between self-efficacy and control performance. They stated that performance of complex activities is affected by self-efficacy in that individuals of high efficacy display more strategic flexibility, manage their time more efficiently and discard flawed strategies more quickly than others. Moreover, self-efficacy has been found to moderate the relationship between acquired knowledge and control performance (Kluge 2008). Thus, a positive relationship between selfefficacy and process control performance is assumed.

\subsubsection{Personality}

Personality traits such as conscientiousness, openness and emotional stability have been found to be related to work performance (e.g. Barrick and Mount 1991). In a meta-analysis by Barrick and Mount (1991), conscientiousness was related to performance for a range of occupational groups. Similar results have been found for pilots' performance, where conscientiousness was the strongest predictor (Pettitt and Dunlap 1995, cited Wickens et al. 1998, p. 559). Conscientiousness is believed to be particularly important for safety in process control, for many processes involve high risk and hazardous materials (Wickens and Hollands 2000). Concerning emotional stability, Bartram (1995) found that pilots who successfully completed the training programme were more emotionally stable than pilots who had not. Accordingly, it is believed that the personality traits of conscientiousness, openness and emotional stability correlate with process control performance.

\subsection{Present study}

The aim of this study was to examine the relationship between operator characteristics and performance in the field of process control. More precisely, cognitive ability, cognitive flexibility, self-efficacy and personality have been analysed, which previous studies have shown to be related to performance.

Operator performance as a criterion was measured in a simulated process control environment. The datagathering facilities of the computer-based simulation made it possible to track various process control performance variables and measure both primary and secondary tasks. As primary tasks, system control and diagnostic performance were measured to take account of the independent character of the tasks. Since ability in system control is independent of ability in fault diagnosis (Landeweerd 1979), a competent controller may not necessarily be a competent diagnostician and vice versa (Wickens and Hollands 2000). As secondary tasks, regular recording of tank levels and acknowledgement of system alarms were also required of the operator. This setting consisting of primary and secondary tasks corresponded to a complex multitask environment.

The operator characteristics (cognitive ability, cognitive flexibility, self-efficacy and personality) that are expected to be predictors of process control performance were measured through various questionnaires.

A training session was conducted to instruct participants in the process control task. A testing session took place 1 week later. The issue of training effectiveness for process control environments was also examined in this study. The findings of this research question are reported in a separate article (Sauer et al. 2008). In the present article, the focus is on operator characteristics and its relation to performance.

\section{Method}

\subsection{Participants}

The study involved 39 participants (51.3\% female) who were trainee operators at different Swiss chemical companies employing process control environments in their production systems. Participants with this background were sought for the sample to ensure that they had an understanding and knowledge of technical systems. As the trainees were given two half days off work to take part in the study it was not possible for the collaborating organisations to provide a larger 
sample of participants. Participants' ages ranged from 16 to 22 years (mean 18.1).

\subsection{Training}

Two different kinds of training were given. The participants in the control group received basic training after a procedure-centred approach, whereas the participants in the experimental group received additional heuristic rule training. The training and the findings on its effects are described in more detail in a separate article (Sauer et al. 2008). The training sessions lasted approximately $4 \mathrm{~h}$ in total. Training duration was limited to half a day, as it is current practice in some organisations (e.g. in chemical industries, Kluge et al. in press). The sessions were conducted with groups of nine or 10 participants working alone on individual computers. There were two training sessions based on procedure-centred approaches used in previous studies (e.g. Hockey et al. 2007). Heuristic rules were presented to one training group $(n=19)$, with the other group receiving a comparable task $(n=20)$.

Analyses were conducted on the whole sample. The authors did not expect any interaction effects of training method and operator characteristics on performance due to the considerable overlap of the training methods in their content. The two training approaches differed only in that in one group heuristic rules were added to the procedure-based training (totalling $25 \mathrm{~min}$ ). Furthermore, there was no theory that would suggest an interaction of heuristic rule training and individual characteristics. However, to test that the assumptions were correct, the correlations between operator characteristics and performance were also statistically analysed as a function of training group, but the correlations revealed no relevant differences between the groups (Fisher's r-to-z transformation, all $p>0.05$ ). Thus, training was not found to have a moderating effect on the relationship between operator characteristics and performance.

\subsection{Process control task}

Process control performance was assessed by using a computer-based simulation of a complex task called Cabin Air Management System (CAMS). CAMS has already been applied in a number of previous studies (e.g. Hockey et al. 2007). As the task has been described elsewhere (Sauer et al. 2000b), it will be outlined only briefly here. CAMS simulates a spacecraft's automated life-support system, but its underlying principles are analogous to a process control task. The operator must monitor the system

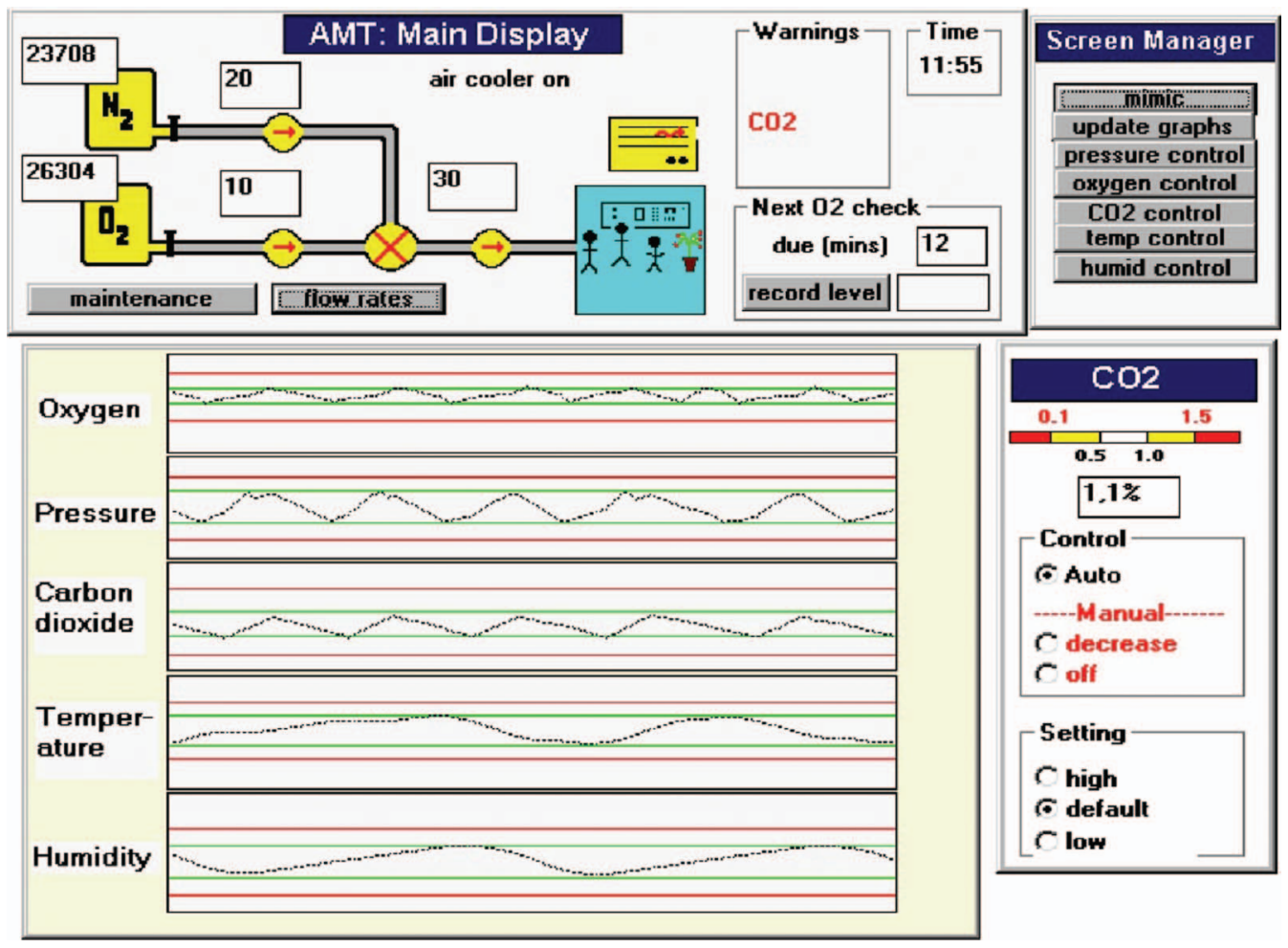

Figure 1. Main display of Cabin Air Management System. 
and intervene if a system fault occurs. CAMS consists of five main system variables $\left(\mathrm{O}_{2}, \mathrm{CO}_{2}\right.$, cabin pressure, temperature and humidity) that are maintained in a predefined zone by automatic controllers. The operator must complete four tasks with different priorities according to their importance for crew survival. Two of the tasks are defined as primary (system control and fault diagnosis) and two as secondary (prospective memory and reaction time; see below). Figure 1 shows the main display of CAMS with the screen manager, warning panel, history display, flow meters and its current values and control panels for the five main system variables.

\subsection{Assessment of operator characteristics}

Operator characteristics were assessed before the training session. The completion of the questionnaires took approximately $45 \mathrm{~min}$.

\subsubsection{Cognitive abilities}

The Wonderlic Personnel Test (Wonderlic Inc. 2002) was used to measure cognitive abilities. The test consists of 50 items and captures verbal, numerical and figural aspects of intelligence and learning aptitude. The test questions included word comparisons, story problems and number series (e.g. 'What is the next number in this series? $\left.10.50 .250 .125^{\prime}\right)$. The participants had 12 min to work on the multiple-choice test.

\subsubsection{Cognitive flexibility}

Cognitive flexibility was measured with an adapted version of the Cognitive Flexibility Inventory (Spiro et al. 1996), which captures high and low cognitive flexibility. The scale consisted of three subscales that represent: (a) the preference to decompose complexity into parts vs. holism ('leaving complexity as it is'); (b) passive reception of information vs. active construction of information ('constructing knowledge'); (c) external vs. personal control of learning ('self-directed learning'). A 9-point scale ranging from -4 (one statement) to +4 (vs. other statement) was employed. A sample item from the scale was: 'Learning works best under the guidance of experts (e.g. teachers) vs. learning works best when it is self-directed'. Cronbach's alpha of the adapted German version was 0.70 .

\subsubsection{Self-efficacy}

Self-efficacy was measured with eight items using Schyns and Collani's (2002) self-efficacy scale. A 6point scale ranging from 0 to $100 \%(0 \%, 20 \%, 40 \%$,
$60 \%, 80 \%, 100 \%$ ) was employed. Internal

consistency of the adapted German version of the selfefficacy scale was satisfactory (Cronbach's alpha $=0.82)$ and similar to the original version $($ Cronbach's alpha $=0.88)$. A sample item from the scale was: 'When I am confronted with a problem in my job, I can usually find several solutions'.

\subsubsection{Personality traits}

Assessment of conscientiousness, openness and emotional stability was based on Saucier's (1994) Big-five Markers. Eight adjectives per personality trait (24 items total) had to be rated by participants on a 9-point scale ranging from 1 (extremely inaccurate) to 9 (extremely accurate). (Item examples for conscientiousness: organised, systematic, careless; for openness: creative, intellectual, complex; and for emotional stability: relaxed, moody, touchy.)

\subsection{Performance measures}

The data-gathering facilities of CAMS allow the measurement of performance criteria, including primary and secondary task performance. System control and fault diagnosis were defined as primary tasks; prospective memory and reaction time as secondary tasks (Sauer et al. 2000b).

\subsubsection{System control}

The operator must maintain five key parameters within a predefined zone. If a key parameter departs from the target zone, it can be restored to the proper level through adjustments of automatic controllers or adaptation of manual control. The duration of the parameters' deviation from the predefined zone was measured in seconds and converted into percentages.

\subsubsection{Fault diagnosis}

If a system fault occurs, the operator is required to diagnose and remedy it by means of the maintenance facility. One measure of diagnostic performance was the rate of faulty diagnoses; the other was the number of seconds the operator needed to remedy the system fault correctly.

\subsubsection{Prospective memory}

This secondary task involves the recording of $\mathrm{O}_{2} \operatorname{tank}$ levels every $3 \mathrm{~min}$, a task corresponding to a prospective memory task (e.g. Brandimonte et al. 1996). Omitted tank-level recordings were counted. 


\subsubsection{Reaction time}

The other secondary task is to acknowledge alarms when a warning signal appears. Reaction time is thereby measured. As false alarms can occur, the corresponding parameter must be examined after the acknowledgement.

\subsubsection{System knowledge}

Declarative knowledge (knowledge about the system and the relationship between the parameters) was assessed through a questionnaire. The latter has been employed before and is described in more detail in Sauer et al. (2000a). It consists of 12 multiple-choice items (e.g. 'What happens to pressure when the $\mathrm{CO}_{2}$ scrubber is on?') with three alternatives ('increase', 'decrease', 'minimal or no effect'). Each set of alternatives was followed by an open question to explain the given answer ('Please explain why') and by three open questions about the processes and relationships in the CAMS environment (e.g. 'Please explain which components or processes have an impact on temperature in the cabin and describe the direction of the relationship'). Participants scored from 2.5 to 16.5 points of a possible 21 points (mean 10.0).

\subsection{Procedure}

The training session lasted approximately $5 \mathrm{~h}$, including the completion of the questionnaires. The testing session lasted $2 \mathrm{~h}$. Performance was measured in the testing session that was held 1 week after the training session in the same groups as the training. The participants worked on their individual computers for $70 \mathrm{~min}$ (two 35 -min testing sessions), as they had done in their training. During the testing, they had to deal with three practised faults (faults they had trained to respond to), three novel faults (similar to practised faults, but not previously encountered) and two complex faults (which required an indirect way of handling the given fault) according to a schedule unknown to them. During the training session, the participants received a fault-finding guide, which they were also permitted to use in the testing session.

\section{Results}

\subsection{Correlations between operator characteristics and process control performance}

Data points more than 1.5 interquartile ranges away from the interquartile range were regarded as outliers. Two such outliers were identified for system control performance and were removed. One data record was missing because of technical problems. In this section, data of 36 participants are reported.

The overall pattern of the correlations between operator characteristics and process control performance revealed significant relationships between cognitive ability and performance and between cognitive flexibility and performance (see Table 1). Cognitive ability was significantly correlated with system control and system knowledge. Cognitive flexibility was significantly associated with both system control and diagnostic performance but, notably, in different directions. Participants with low cognitive flexibility generally performed better in system control than participants with high cognitive flexibility, whereas the latter participants tended to outperform the former in fault diagnosis and repair. There were no significant relationships between self-efficacy or personality and process control performance.

\subsubsection{Cognitive ability}

Cognitive ability was significantly correlated to system control failures $\left(r_{s}=-0.31, p<0.05\right)$. That is, individuals with high cognitive abilities showed better

Table 1. Spearman correlations between operator characteristics and performance.

\begin{tabular}{|c|c|c|c|c|c|c|}
\hline Performance measure & $\begin{array}{c}\text { Cognitive } \\
\text { ability }\end{array}$ & $\begin{array}{l}\text { Cognitive } \\
\text { flexibility }\end{array}$ & $\begin{array}{c}\text { Self- } \\
\text { efficacy }\end{array}$ & $\begin{array}{l}\text { Conscien- } \\
\text { tiousness }\end{array}$ & Openness & $\begin{array}{c}\text { Emotional } \\
\text { stability }\end{array}$ \\
\hline \multicolumn{7}{|l|}{ Primary task performance } \\
\hline System control failures & $-0.31 *$ & $0.34 *$ & -0.18 & -0.15 & -0.04 & -0.02 \\
\hline Diagnostic errors & -0.17 & $-0.31 *$ & -0.24 & -0.22 & -0.14 & 0.00 \\
\hline Fault identification time & -0.19 & $-0.35^{*}$ & -0.18 & -0.13 & -0.01 & 0.03 \\
\hline \multicolumn{7}{|l|}{ Secondary task performance } \\
\hline Prospective memory failures & 0.08 & 0.06 & 0.02 & -0.09 & 0.23 & -0.15 \\
\hline Reaction time & -0.13 & -0.16 & -0.01 & -0.07 & 0.04 & 0.02 \\
\hline System knowledge & $0.41 * *$ & 0.06 & 0.15 & -0.05 & 0.14 & -0.27 \\
\hline
\end{tabular}

$* p<0.05 ; * p<0.01$ (one-tailed) 
system control performance than did participants with low cognitive ability. A significant relationship between cognitive ability and system knowledge was also found $\left(r_{s}=0.41, p<0.01\right)$. In other words, the higher the cognitive abilities, the better the declarative knowledge.

There was no significant relationship between cognitive ability and overall diagnostic performance (diagnostic errors: $r_{s}=-0.17, p>0.05$; fault identification time: $\left.r_{s}=-0.19, p>0.05\right)$. However, an additional analysis for diagnostic performance of practised and novel faults showed that cognitive ability was significantly related to dealing with novel faults, both in diagnostic errors $\left(r_{s}=-0.30, p<0.05\right)$ and fault identification time $\left(r_{s}=-0.32, p<0.05\right)$. Cognitive ability was not significantly related to managing practised faults, though (diagnostic errors: $r_{s}=-0.07$, $p>0.05$; fault identification time: $r_{s}=-0.01$, $p>0.05)$.

\subsubsection{Cognitive flexibility}

Cognitive flexibility was significantly related to system control failures $\left(r_{s}=0.34, p<0.05\right)$. According to this finding, participants with low cognitive flexibility tended to perform better on system control than did participants of high cognitive flexibility. An opposing pattern of correlations was found for diagnostic performance, with high cognitive flexibility being associated with accurate fault diagnosis $\left(r_{s}=-0.31\right.$, $p<0.05)$ and fault identification time $\left(r_{s}=-0.35\right.$, $p<0.05)$.

Examination of the subscales of the overall cognitive-flexibility scale (see Table 2) shows that the sub-scale 'constructing knowledge' in particular explains these correlations. Participants who took initiative and constructed their knowledge tended to perform better than those who rather recalled rigid prescriptions from memory in both accuracy of fault diagnosis $\left(r_{s}=-0.30, p<0.05\right)$ and fault identification time $\left(r_{s}=-0.34, p<0.05\right)$. The participants who took initiative and constructed their knowledge also seemed to gain a superior understanding of the system, although this correlation was only marginally significant $\left(r_{s}=0.27, p=0.052\right)$. By contrast, system control was correlated to a cognitive style in which the individual prefers passively receiving information and knowledge to constructing knowledge $\left(r_{s}=0.29\right.$, $p<0.05)$.

\subsubsection{Self-efficacy and personality}

Contrary to the hypotheses, self-efficacy and the personality traits showed no significant relationships to process control performance. See Table 1 for corresponding correlation coefficients.

\subsection{Regression analysis with operator characteristics and performance}

A hierarchical regression analysis was conducted, with system control failures serving as the criterion and with cognitive ability, cognitive flexibility and system knowledge serving as predictors (Table 3). The selection of predictors and their order of entry was based on past research, as recommended by Field (2005). Cognitive ability was therefore entered first, as past work indicated that cognitive ability was a strong predictor of performance (Schmidt and Hunter 1998; see section 1.2.1). System knowledge was added as a further predictor because it also correlated with system control performance.

All predictors showed significant correlations with the criterion. Cognitive flexibility and system knowledge were significant predictors of system control performance $(p<0.05)$. Cognitive ability accounted for $8 \%$ of the variation in system control performance; cognitive flexibility, for $10 \%$. Inclusion of system knowledge made it possible to explain an additional $11 \%$ of the variation in system control. Overall, the two operator characteristics, cognitive ability and cognitive flexibility, together with system knowledge account for almost $30 \%$ of the variation in system control performance.

Table 2. Spearman correlations between sub-scales of cognitive flexibility and performance.

\begin{tabular}{|c|c|c|c|}
\hline Performance measure & $\begin{array}{c}\text { Leaving complexity } \\
\text { as it is }\end{array}$ & $\begin{array}{l}\text { Constructing } \\
\text { knowledge }\end{array}$ & $\begin{array}{l}\text { Self-directed } \\
\text { learning }\end{array}$ \\
\hline \multicolumn{4}{|l|}{ Primary task performance } \\
\hline System control failures & 0.09 & $0.29 *$ & 0.14 \\
\hline Diagnostic errors & -0.09 & $-0.30 *$ & -0.15 \\
\hline Fault identification time & -0.25 & $-0.34 *$ & -0.10 \\
\hline System knowledge & 0.05 & 0.27 & -0.06 \\
\hline
\end{tabular}

$* p<0.05$. 
The same hierarchical regression analysis was carried out with diagnostic performance as a criterion and with cognitive ability, cognitive flexibility and system knowledge as predictors. The analyses revealed no significant predictors for diagnostic errors, fault identification time (see Table 4), or the secondary task performance measures.

\section{Discussion}

The primary goal of this study was to improve understanding of the relationship between operator characteristics and process control performance. Cognitive ability and cognitive flexibility emerged as the best predictors of process control performance. An important finding was that there were differences between the predictors of system control performance and diagnostic performance. All these findings are relevant to operator selection.

There are two major findings in this study, which both have implications for personnel selection. The first major finding was that cognitive ability was a good predictor for process control performance and

Table 3. Summary of hierarchical regression analysis with system control failures as a criterion.

\begin{tabular}{lrcrc}
\hline $\begin{array}{l}\text { Predictors of system } \\
\text { control failure }\end{array}$ & $B$ & $S E B$ & $\beta$ & Significance \\
\hline $\begin{array}{l}\text { Step 1 } \\
\text { Cognitive ability }\end{array}$ & -0.31 & 0.18 & -0.28 & 0.093 \\
Step 2 & & & & \\
Cognitive ability & -0.39 & 0.18 & -0.36 & 0.034 \\
Cognitive flexibility & 1.76 & 0.87 & 0.33 & 0.051 \\
Step 3 & & & & \\
Cognitive ability & -0.19 & 0.19 & -0.17 & 0.327 \\
Cognitive flexibility & 1.70 & 0.83 & 0.32 & 0.047 \\
System knowledge & -0.65 & 0.30 & -0.37 & 0.036 \\
\hline$R^{2}=0.08$ rep $1 ; \Delta R^{2}$ & -0.10 & & & \\
\end{tabular}

$R^{2}=0.08$ for step $1 ; \Delta R^{2}=0.10$ for step $2 ; \Delta R^{2}=0.11$ for step 3 .

Table 4. Summary of hierarchical regression analysis with fault identification time as a criterion.

\begin{tabular}{lcccc}
\hline $\begin{array}{l}\text { Predictors of fault } \\
\text { identification time }\end{array}$ & $B$ & $S E B$ & $\beta$ & Significance \\
\hline $\begin{array}{l}\text { Step 1 } \\
\text { Cognitive ability }\end{array}$ & -0.89 & 0.75 & -0.20 & 0.244 \\
Step 2 & & & & \\
Cognitive ability & -0.65 & 0.76 & -0.15 & 0.394 \\
Cognitive flexibility & -5.10 & 3.77 & -0.23 & 0.185 \\
Step 3 & & & & \\
Cognitive ability & -0.40 & 0.87 & -0.09 & 0.647 \\
Cognitive flexibility & -5.18 & 3.81 & -0.23 & 0.184 \\
System knowledge & -0.82 & 1.37 & -0.11 & 0.556 \\
\hline$R^{2}=0.04$ for step 1; $\Delta R^{2}=0.005$ for step $2 . \Delta R^{2}=0.01$ for step 3
\end{tabular}

$R^{2}=0.04$ for step $1 ; \Delta R^{2}=0.005$ for step $2 ; \Delta R^{2}=0.01$ for step 3 . for diagnostic performance (though the association was only observed for novel faults and not for practised ones). Cognitive ability was also significantly correlated with system knowledge. With regard to system knowledge, Schmidt and Hunter (1998) argue that cognitive ability indirectly affects performance through the acquisition of job knowledge. Presumably, cognitive ability also indirectly affects system control performance by the same route, but the current sample was too small to permit an accurate examination of this possibility.

Cognitive ability and cognitive flexibility together with declarative knowledge account for nearly $30 \%$ of the variance in system control. The effect sizes in this study are similar to findings in the meta-analysis by Schmidt and Hunter (1998), who reported relationships of $r=0.51$ between cognitive ability and work performance $\left(\mathrm{R}^{2}=26 \%\right)$. The similar effect sizes also suggest some ecological validity of the present experiment since the present findings were comparable to results obtained in real work environments.

The second major finding of the study was that cognitive flexibility was a good predictor of process control performance, but the effects emerged in different directions for the two tasks fault diagnosis and system control. Operators with high cognitive flexibility outperformed operators with low cognitive flexibility on fault diagnosis, whereas the reverse was true for system control (i.e. low cognitive flexibility was associated with better performance). This suggests that the most appropriate level of cognitive flexibility is task-dependent to the extent that the positive effects of a certain level may not only be neutralised under a different task but might even turn to a disadvantage. This supports Landeweerd's (1979) finding that operator skills in system control and in fault diagnosis are independent of each other. Taken together, these findings show that performance of the two main tasks of process control are supported by different levels of cognitive flexibility. While these differences should be considered in personnel selection, they entail a dilemma since operators will be required to be good at both system control and fault diagnosis. There are several possibilities to deal with that dilemma. First, operators with a medium score in cognitive flexibility may be selected to avoid very poor performance on either of the two process control tasks. This approach favours generalists rather than specialists. However, while this would prevent the selection of operators who perform very poorly at one of the tasks, the downside would be that these operators will not excel at any of the tasks. Second, a task analysis is conducted to determine if any of the two tasks is more important than the other for overall performance in a specific 
work context. For instance, in some organisations operators are only expected to carry out system control tasks while senior colleagues are responsible for diagnostic tasks (Williams and Taylor 1993). In that case, levels of required cognitive flexibility could be adjusted accordingly. Third, if process control tasks are carried out in teams, a possible solution may be to build diverse teams whose members are matched for their cognitive style (e.g. high- and low-flexibility operators are members of the same team). This approach may be promising because cognitive diversity in teams has been shown to benefit system control performance and diagnostic performance (Sauer et al. 2006). Overall, the task dependency of cognitive flexibility adds an additional layer of complexity to the literature on cognitive styles, which has generally assumed that although bipolar dimensions represented two equally efficient ways of solving a task, in reality, one strategy was usually more effective than the other' (Kozhevnikov 2007, p. 466). Furthermore, the cognitive flexibility scale was especially developed for complex and ill-structured tasks, which has been identified as a particular need in the humancomputer domain (Hockey 1990).

In addition to the demonstrated utility of the cognitive ability and cognitive flexibility tests, it is of special practical interest to note that these instruments are relatively inexpensive, quick and easy to administer. For example, the Wonderlic ability test takes $12 \mathrm{~min}$ to complete and the cognitive flexibility questionnaire about $5 \mathrm{~min}$. Due to these advantages, the cognitive ability and cognitive flexibility tests compare favourably to other methods employed in personnel selection, such as interviews.

When looking at the overall pattern of association between operator characteristics and performance, some of the correlations predicted by the literature were not found in the present study. This may be due to environmental variables (e.g. presence of stressors) or the training approach. For example, one may presume that emotional stability as a personality factor might become more relevant with increasing work pressure and stress levels. Similarly, in a training approach as used in the present study, few degrees of freedom are provided to operators compared to other training approaches. This may generally lead to individual characteristics becoming less relevant (cf. Mischel 1968).

The influence of different interventions on the relationship between operator characteristics and performance needs to be examined to advance the understanding of the individual correlates of process control performance. With appropriately designed interventions, operators could be better supported, matching cognitive styles and abilities. For example, one may consider a training method in which the emphasis and training time on specific tasks is varied according to individual operator needs (cf. emphasis shift training; Gopher 2007). This may be in the form of exercises emphasising fault diagnosis (for operators with low cognitive flexibility because they are generally less good at this task) or system control (for operators with high cognitive flexibility because they are generally less good at this task).

Finally, recommendations for future research on operator characteristics are given. The present study was of an exploratory nature since empirical results on operator characteristics, especially cognitive flexibility, are quite scarce. Therefore, further research is needed to test whether the results found in this study can be replicated and whether they can be applied to different settings. For instance, the experiment involved trainee operators at the beginning of their vocational careers. This needs to be complemented with work using real operators to examine whether the results would hold true for more experienced operators.

\section{Acknowledgements}

This project has been partly funded by the Swiss National Science Foundation (No. P001-106354).

\section{References}

Barrick, M.R. and Mount, M.K., 1991. The Big Five personality dimensions and job performance: A meta-analysis. Personnel Psychology, 44, 1-26.

Bartram, D., 1995. The predictive validity of the EPI and $16 \mathrm{PF}$ for military flying training. Journal of Occupational and Organizational Psychology, 68, 219-236.

Brandimonte, M., Einstein, G.O., and McDaniel, M.A., 1996. Prospective Memory: Theory and Applications. Hillsdale: Erlbaum.

Colquitt, J.A., LePine, J.A., and Noe, R.A., 2000. Toward an integrative theory of training motivation: A metaanalytic path analysis of 20 years of research. Journal of Applied Psychology, 85, 678-707.

Debowski, S., Wood, R.E., and Bandura, A., 2001. Impact of guided exploration and enactive exploration on self-regulatory mechanisms and information acquisition through electronic search. Journal of Applied Psychology, 86, 1129-1141.

Field, A., 2005. Discovering statistics using SPSS, 2nd ed. London: SAGE Publications.

Gopher, D., 2007. Emphasis change as a training protocol for high-demand tasks. In: A.F. Kramer, D.A. Wiegmann, and A. Kirlik, eds. Attention: From theory to practice. Oxford: Oxford University Press, 209-224.

Hockey, G.R.J., 1990. Styles, skills and strategies: Cognitive variability and its implications for the role of mental models in HCI. In: D. Ackermann and M.J. Tauber, eds. Mental models and human-computer interaction 1. North-Holland: Elsevier, 113-129.

Hockey, G.R.J., Sauer, J., and Wastell, D.G., 2007. Adaptability of training in simulated process control: Comparison of knowledge- and rule-based guidance under task changes and environmental stress. Human Factors, 49, 158-174. 
Hollnagel, E., 1998. Cognitive reliability and error analysis method. Oxford: Elsevier Science Ltd.

Hunter, D.R. and Burke, E.F., 1994. Predicting aircraft pilot training success: A meta-analysis of published research. The International Journal of Aviation Psychology, 4, 297 313.

International Atomic Energy Agency, 1996. Nuclear power plant personnel training and its evaluation: A guidebook. Executive summary, IAEA-TECDOC-1411. Vienna: International Atomic Energy Agency.

International Atomic Energy Agency, 2002. Recruitment, qualification and training of personnel for nuclear power plants. Safety Standard Series, No. NS-G-2.8. Vienna: International Atomic Energy Agency.

International Atomic Energy Agency, 2006. Competency assessments for nuclear industry personnel. Vienna: International Atomic Energy Agency.

Kluge, A., 2008. What you train is what you get? Task requirements and training methods in complex problemsolving. Computers in Human Behavior, 24, 284-308.

Kluge, A., et al., in press. Designing training for process control simulators: A review of empirical findings and current practices. Theoretical Issues in Ergonomics Science.

Landeweerd, J.A., 1979. Internal representation of a process, fault diagnosis and fault correction. Ergonomics, 22, 1343-1351.

Mischel, W., 1968. Personality and assessment. New York: Wiley.

Morris, N.M. and Rouse, W.B., 1985. Review and evaluation of empirical research in troubleshooting. Human Factors, 27, 503-530.

Saucier, G., 1994. Mini-markers: A brief version of Goldberg's unipolar big-five markers. Journal of Personality Assessment, 63, 506-516.

Sauer, J., Hockey, G.R.J., and Wastell, D.G., 2000a. Effects of training on short- and long-term skill retention in a complex multiple-task environment. Ergonomics, 43, 2043-2064.

Sauer, J., Wastell, D.G., and Hockey, G.R.J., 2000b. A conceptual framework for designing microworlds for complex work domains: A case study of the Cabin Air Management System. Computers and Human Behavior, $16,45-58$
Sauer, J., et al., 2006. Cognitive diversity and team performance in a complex multiple-task environment. Ergonomics, 10, 934-954.

Sauer, J., et al., 2008. The effects of heuristic rule training on operator performance in a simulated process control environment. Ergonomics, 51, 953-967.

Schmidt, F.L. and Hunter, J.E., 1998. The validity and utility of selection methods in personnel psychology: Practical and theoretical implications of 85 years of research findings. Psychological Bulletin, 124, 262-274.

Schyns, B. and Collani, G., 2002. A new occupational selfefficacy scale and its relation to personality constructs and organizational variables. European Journal of Work and Organizational Psychology, 11, 219-241.

Spiro, R.J., Feltovich, P.J., and Coulson, R.L., 1996. Two epistemic world-view: prefigurative schemas and learning in complex domains. Applied Cognitive Psychology, 10, $51-61$

Stajkovic, A.D. and Luthans, F., 1998. Self-efficacy and work-related performance: A meta-analysis. Psychological Bulletin, 124, 240-261.

Stanton, N. and Ashleigh, M., 1996. Selecting personnel in the nuclear power industry. In: N. Stanton, ed. Human factors in nuclear safety. London: Taylor \& Francis, 159 186.

Wickens, C.D., Gordon, S.E., and Liu, Y., 1998. An introduction to human factors engineering. New York: Addison Wesley.

Wickens, C.D. and Hollands, J.G., 2000. Engineering psychology and human performance, 3rd ed. Upper Saddle River: Prentice Hall.

Williams, J.C. and Taylor, S.E., 1993. A review of the state of knowledge and of current practice in selection techniques for process operators, HSE contract research report No. 58. London: HMSO.

Wittmann, W.W. and Hattrup, K., 2004. The relationship between performance in dynamic systems and intelligence. Systems research and Behavioural Science, 21, 393-409.

Wonderlic, 2002. Wonderlic Personnel Test. Libertyville: Wonderlic Inc. 